\title{
Heteronormatividad y diversidad sexual en la formación del profesorado: Estudio etnográfico en una escuela Normal de la Ciudad de México
}

\author{
Heteronormativity and sexual diversity in teachers' training: \\ an ethnographic study in a teachers' college in Mexico City
}

DOI: https://doi.org/10.32870/dse.v0i21.678

\author{
Rey Jesús Cruz Galindo*
}

\begin{abstract}
Resumen
En este artículo se presentan los resultados finales de una investigación en la que el objeto estudio fue la diversidad sexual y la heteronormatividad en la educación. El objetivo general fue interpretar cómo son las prácticas y los discursos respecto a la diversidad sexual en la formación inicial de futuros docentes. El estudio se realizó en la Escuela Normal Superior de México, institución formadora de docentes para escuelas secundarias. La investigación tiene un enfoque cualitativo, específicamente etnográfico. Las técnicas de investigación consistieron en observaciones de la práctica escolar y entrevistas a docentes y estudiantes. Los hallazgos más importantes que arrojó esta pesquisa son: existe una enseñanza normalizada de la sexualidad en la formación docente; en ese orden de ideas, este modelo sexual hegemónico establece socialmente al docente como un modelo heteronormativo en la escuela.
\end{abstract}

Palabras clave: heteronormatividad - diversidad sexual - formación docente - homofobia - sexualidad.

\begin{abstract}
This article presents the final results of research on sexual diversity and heteronormativity in education. The general objective was to interpret the practices and discourses about sexual diversity in the initial training of future teachers. The study was conducted at the Escuela Normal Superior de México with a qualitative - namely ethnographic - approach. The research techniques were observations of school practice and interviews with teachers and students. The most important findings were that there is a normalized teaching of sexuality in teacher education; thus, this hegemonic sexual model establishes the teacher as a heteronormative model at school.
\end{abstract}

Key Words: heteronormativity - sexual diversity - teacher training - homophobia - sexuality.

*Maestro en Ciencias con especialidad en Investigaciones Educativas. Líneas de investigación: diversidad sexual en educación, formación docente y educación inclusiva, pedagogía social e intervención educativa. Coordinador académico del Centro de Formación Docente de la Universidad del Valle de Puebla. México. rey.jesuscg@gmail.com 


\section{¿Por qué investigar sobre diversidad sexual en la formación del profesorado?}

El debate sobre la diversidad sexual en las instituciones educativas me ha interesado esencialmente para reflexionar sobre el papel de la escuela como una institución que tanto puede ser un espacio emancipador, transgresor y constructor de ciudadanía que permita el reconocimiento de la diversidad sexual ( $y$ de cualquier otra población escolar vulnerable), como puede ser un lugar disciplinario en donde se reproduce la violencia contra quienes no cumplen con la heteronormatividad.

Por un lado, por heteronormatividad se entiende la forma de ver el mundo a partir de dos sexos, dos géneros y legitimando a la heterosexualidad como la única orientación sexual aceptada social y culturalmente (Wittig, 2006; Núñez, 2016; Carrera, Lameiras y Rodríguez, 2013). Y por otro, Muñoz (2010) señala que este modelo patriarcal-judeocristiano-capitalista de la sexualidad comprende cuatro elementos: la monogamia, la falocracia, el reproduccionismo y la heterosexualidad.

Aunado a lo anterior, me parece que la escuela tiene ciertos lineamientos pedagógicos - visibles e invisibles, explícitos e implícitos - que han señalado una sola manera de ser y estar. ${ }^{1}$ La escuela es una institución con un poder disciplinario homogéneo y continuo, que vigila y castiga el tiempo, la actividad, la manera de ser, la palabra, el cuerpo y la sexualidad (Foucault, 2009).

El papel del profesorado es trascendental en la vida escolar, ya que a partir del trabajo docente es posible construir aprendizajes o experiencias educativas; de tal manera que la docencia puede ser una labor que genere ambientes educativos de apertura y diálogo sobre la diversidad sexual, siempre y cuando quienes estén al frente de esta noble tarea hayan recibido una formación laica y humanista sobre la sexualidad. Siguiendo a Morgade y Alonso (2008: 38), "los y las docentes son sujetos clave, tanto en la producción pedagógica en general como en la mirada global que éstos/as lleguen a construir en forma colectiva sobre la subjetividad y las relaciones sociales". Por lo tanto, la docencia tiene bastantes implicaciones en la educación sexual y la cultura escolar.

Todo esto tiene que ver también con el análisis de otros aspectos que se relacionan con la sexualidad y que pueden promover ciudadanía en las escuelas: el cuerpo, el género, las orientaciones sexuales, lo étnico-racial, las clases sociales y lo generacional (Werner, 2008). Para ser más específico, es indispensable pensar y reconocer que en la escuela existe diversidad de docentes, diversidad de estudiantes, diversidad dentro de las familias, y que la heteronormatividad alude a la existencia de la homofobia, lesbofobia, bifobia y transfobia en los centros educativos (Sánchez, 2009).

1 Es indispensable señalar que a nivel nacional existe un modelo de educación arraigado a una visión religiosa judeocristiana "que naturaliza y normaliza la sexualidad humana porque la considera un hecho fisiológico y anatómico con fines reproductivos" (Hernández- Rosete, Flores y Echavarría, 2011: 472).

Diálo pos 
Es menester entonces tener un acercamiento a los conocimientos sobre diversidad sexual que están recibiendo los futuros docentes de educación secundaria, puesto que van a trabajar con adolescentes que pueden estar inmersos en situaciones de discriminación o vulneración de sus derechos como personas. Incluso, el hecho de que los y las docentes no conozcan sobre el tema, no les exime de la responsabilidad social que tienen como formadores de personas. De tal modo, resulta indispensable ciudadanizar el derecho a la diferencia y, sobre todo, el derecho a la diversidad.

Aunado a lo anterior, es importante mencionar que en México, de manera general, la investigación educativa enfocada a la diversidad sexual ha tenido que ver con la visibilidad de la homofobia en los centros escolares, el papel del profesorado frente a la diversidad sexual, así como con la construcción de identidades en estudiantes y docentes LGBT y las resistencias frente a la discriminación. La mayoría de las investigaciones se han efectuado en zonas urbanas y en instituciones de nivel superior, pero también, aunque con menor profundidad, en las de media superior y básico (solo escuelas secundarias).

\section{El marco metodológico. Una investigación etnográfica sobre la diversidad sexual en la formación docente}

Es así como, con el objetivo de hacer visible lo invisible en la escuela ${ }^{2}$ respecto a la diversidad sexual en la formación de futuros docentes, tomé la decisión de realizar un estudio etnográfico en la Escuela Normal Superior de México (ENSM). Esta institución ha formado por décadas a docentes de educación básica, específicamente, para escuelas secundarias en la Ciudad de México.

El estudio tiene como propósito la comprensión e interpretación de lo que ocurre en la escuela, pero no tiene fines explicativos. La importancia de esta investigación etnográfica radica en desentrañar estructuras y universos de sentido y significación socialmente establecidos (Geertz, 2003). Para clarificar lo que ocurre en la escuela y aportar a su universo de conocimiento se partió de la observación, el registro y análisis de datos. Las observaciones se realizaron en salones de clase y otros espacios escolares como la explanada, la cafetería y algunos departamentos académicos y administrativos. El mayor registro de datos se obtuvo mediante entrevistas semiestructuradas a profundidad, realizadas con tres grupos de informantes.

2 Rockwell (2009: 21), señala que el etnógrafo debe "documentar lo no-documentado de la realidad social [...] En las sociedades modernas, lo no-documentado es lo familiar, lo cotidiano, lo oculto, lo inconsciente". 
Tabla 1. Perfil etnográfico de los informantes

\begin{tabular}{|l|l|}
\hline Grupo I & $\begin{array}{l}\text { Número de } \\
\text { informantes }\end{array}$ \\
\hline $\begin{array}{l}\text { Estudiantes gays, lesbianas y bisexuales, entre } 18 \text { y } 23 \text { años; especia- } \\
\text { lidades de Física, Español y Química. }\end{array}$ & 4 \\
\hline Grupo II & \\
\hline $\begin{array}{l}\text { Personal docente que imparte asignaturas sobre sexualidad, } 2 \text { mu- } \\
\text { jeres y } 4 \text { hombres, entre } 40 \text { y } 63 \text { años; uno de ellos es homosexual y } \\
\text { una de ellas se asume como heteroflexible. }\end{array}$ & 6 \\
\hline Grupo III & 3 \\
\hline Autoridades escolares, todas mujeres de entre 40 y 60 años. & 13 \\
\hline Total & 3 \\
\hline
\end{tabular}

Cabe mencionar que la intención de este estudio no es generalizar el universo de significados que emergieron de los sujetos de investigación; más bien se enfoca en interpretar esos significados de manera contextual y con ciertos límites espacio-temporales. Avanzando en este razonamiento, el objetivo de interactuar con los informantes, principalmente mediante entrevistas, es analizar la intencionalidad de sus acciones. Es decir, lo que busqué fue comprender las razones por las cuales los sujetos actúan de cierta manera (Taylor y Bogdan, 1994). Para ser más específico, me enfoqué en interpretar de qué manera piensan y actúan docentes y estudiantes, en tanto que son partícipes de una institución que normaliza la enseñanza de la sexualidad y reproduce la heteronormatividad en la formación docente.

Durante la realización de este estudio sobre la vida cotidiana en la escuela, se tomó en consideración que los informantes poseen un discurso agenciado y reflexivo; dicho de otro modo, las personas están conscientes de lo que hacen y por qué lo hacen en determinadas relaciones de poder (Giddens, 2003). Con base en el contexto de la ENSM y para efectos de esta investigación, me he enfocado en la interpretación de las relaciones de poder que se dan a partir de la sexualidad, particularmente sobre las orientaciones sexuales y el género. Por tanto, el análisis de las interacciones que observé en la institución se fundamenta en el constructivismo social con enfoque fenomenológico.

En este sentido, se parte de la idea de que el conocimiento acerca de la vida cotidiana se estructura a partir de la importancia y la relevancia que los sujetos le otorgan; asimismo, se entiende que toda acción social tiene una intención significativa y posee un sentido de coherencia. Finalmente, el propósito fue apropiarme de esa coherencia cotidiana a través del trabajo de campo (Berger y Luckmann, 2012). 


\section{El marco de referencia. La construcción social de lo normal y lo patológico en la sexualidad}

De acuerdo con Canguilhem (1971: 187), la palabra normal fue incorporada al lenguaje popular a partir de dos instituciones: la pedagógica y la sanitaria; de ahí viene el nombre de las escuelas normales en Francia. La Escuela Normal surge como una institución en la que se forman docentes y se les enseña el deber ser de la escuela, del profesorado y del estudiantado. Es decir, se crea un prototipo a seguir sobre lo escolar. Normar o normalizar, en este sentido, ha sido "imponer una exigencia sobre una existencia a un dato, cuya variedad y disparidad se ofrecen, con respecto a la exigencia, más aún como algo indeterminado y hostil que simplemente como algo extraño". Por tanto, se considera que lo normal es aquello que cumple con las reglas; de tal manera que lo que se salga de esas normas debe ser corregido, unificado, arreglado.

Adentrándome al análisis etnográfico, durante la entrevista un profesor me dijo lo siguiente:"pues un homosexual, platique con él. Sin tomar aspectos críticos sino hasta que tenga varios casos, y de personas normales; y luego una comparación analógica que es lo correcto" (hombre, docente, 65 años). Lo anterior me lo comentó el profesor mientras trataba de explicarme por qué mi investigación no tenía validez científica por ser cualitativa. Lo que me sorprendió más fue su "analogía" sobre lo que socialmente se construye como lo normal. Esto me lleva a pensar ¿qué tanto persiste la idea de que la homosexualidad $-\mathrm{y}$ cualquier orientación sexual e identidad de género no hegemónica - es algo anormal? ¿qué tiene que ver la escuela con esta normalización de la sexualidad? Lo anterior está relacionado también con el planteamiento histórico que hace Vigarello (2005: 9) sobre las pedagogías y sus poderes en la escuela: "son portadoras de preceptos que dan al cuerpo una forma y lo cuadriculan para someterlo a normas con mayor seguridad aún de lo que haría el pensamiento". En otras palabras, históricamente el poder pedagógico se ha encargado de enseñar "lo correcto" $y$ "lo normal" sobre cómo ser y estar en la escuela.

Los planteamientos anteriores son necesarios para pensar cómo la escuela ha utilizado mecanismos que normalizan la sexualidad. Entiendo como enseñanza normalizada de la sexualidad el modelo sexual hegemónico que se reproduce y legitima en las escuelas: patriarcal, heteronormativo, monógamo y reproductivo. De tal modo que, como lo señala Núñez (2016: 33), la orientación sexual que ha sido normalizada es la heterosexualidad, legítimamente aquella "reproductiva entre hombre masculino y mujer femenina, genitalizada, falocéntrica, orgásmica y en la llamada posición del misionero, en el marco de la institución matrimonial civil y religiosa". Muñoz (2010) recalca que este enfoque reproductivo ha perseguido y condenado a quienes ejercen su sexualidad sin estos fines y da como ejemplos ciertas prácticas: "masturbación, sexo oral, sexo anal, uso de anticonceptivos, y desde luego la homosexualidad, lesbianismo, bisexualidad, transexualidad y transgenericidad" (2010: 49-50). 
Esta enseñanza de la sexualidad atraviesa todos los niveles educativos. Los roles de género son muy puntuales y la sexualidad es presentada de manera genitalizada y reproductiva, es decir, se encuentra enfocada hacia el abordaje de aspectos fisiológicos y deja de lado a los aspectos socioculturales de la sexualidad. Cuando me refiero a la enseñanza normalizada de la sexualidad, tomo como base el planteamiento de la "normalización" que explica Foucault (2009: 213) que realizan las escuelas y el poder disciplinario. Su discusión hace hincapié al definir el "buen encauzamiento" que se pretende lograr en las instituciones: "la penalidad perfecta que atraviesa todos los puntos, y controla todos los instantes de las instituciones disciplinarias, compara, diferencia, jerarquiza, homogeniza, excluye. En una palabra, normaliza".

Entonces, las orientaciones sexuales e identidades de género que no corresponden a estas normas sociales han sido consideradas como degradaciones, anormales, enfermas, indecentes, etcétera (Lizárraga, 2012). Como consecuencia, la institución educativa reproduce estas normas ejerciendo una vigilancia heteronormativa, o sea, aquella "mirada persecutoria dirigida hacia las prácticas sociales que salen del parámetro masculino-femenino, y especialmente a cualquier forma de erotismo que no coincida con los mandatos ligados a la reproducción humana, la monogamia y la heterosexualidad" (Hernández-Rosete y Miskow, 2015: 77).

Finalmente, debo señalar que la enseñanza normalizada de la sexualidad es la base cultural de la homofobia, la lesbofobia, la bifobia y la transfobia en las instituciones educativas. La heteronormatividad no solo afecta a gays, lesbianas, bisexuales o trans, sino también a las personas heterosexuales que no cumplen con los roles de género impuestos desde el nacimiento, esto es, la reproducción de estas mismas normas sexuales.

\section{Los hallazgos etnográficos sobre la enseñanza normalizada de la sexualidad en la formación del profesorado}

\section{El programa de estudios "Desarrollo de los adolescentes II. Crecimiento y Sexualidad": Ia legiti- mación de la heterosexualidad, limitaciones curriculares e invisibilización de la diversidad sexual En la Escuela Normal Superior de México, la formación inicial en sexualidad que reciben quie- nes serán docentes de educación secundaria en la Ciudad de México se encuentra centrada en el modelo hegemónico de la sexualidad que describí anteriormente. Esta formación parte principalmente del binarismo sexual ${ }^{3}$ y del binarismo de género; entendiendo al primero como "la ideología y práctica de construir dos sexos de los cuerpos humanos", y al segundo, como "la noción de que de los cuerpos machos y los cuerpos hembras se derivan naturalmente disposi- ciones diferenciadas de sentir, percibir, pensar y actuar" (Núñez, 2016: 61).}

3 Flores (2010) hace una reflexión acerca de la diferenciación sexual y su relación con la homofobia. Señala que la diferenciación sexual establecida por la biomedicina tiene que ver con las normas e ideales con base en dos sexos únicos.

Diálo pos sobre Educación año 11 | número 21 | julio-diciembre 2020 | ISSN 2007-2171 
Adentrándome en cuestiones curriculares, el plan de estudios que tiene la ENSM es uno de los más atrasados en cuanto a reformas, ya que desde $1999^{4}$ no ha tenido cambio alguno si se compara con otras licenciaturas para educación básica en México. En cuanto a la formación común para todas las especialidades de secundaria, se encuentra una cadena de asignaturas sobre el estudio de la adolescencia en la que aparece la sexualidad como temática: Desarrollo de los adolescentes I: Aspectos generales; Desarrollo de los adolescentes II: Crecimiento y sexualidad; Desarrollo de los adolescentes III: Identidad y relaciones sociales; Desarrollo de los adolescentes IV: Procesos cognitivos y atención educativa a adolescentes en situaciones de riesgo.

Para efectos de esta investigación, me enfoqué en la asignatura Desarrollo de los adolescentes II: Crecimiento y sexualidad. Con la intención de analizar de qué manera se está formando al profesorado, entrevisté a docentes que imparten esta asignatura en la Normal. Este programa es revisado por todos los estudiantes que se encuentran en el segundo semestre de la licenciatura.

En el programa de estudio de la asignatura aparecen temas que son totalmente heteronormativos. Como primer ejemplo, se compara a la identidad sexual con "el otro sexo", o sea, en los contenidos solo aparece lo masculino y lo femenino. Esto me lleva a pensar acerca del binarismo sexual, especialmente en el sentido de que los sexos se oponen. Como segundo ejemplo, el programa se basa en el binarismo de género pues enuncia el tema "la pubertad en relación con los patrones de género" (SEP, 2001a). El asunto aquí es que no se toman en cuenta las identidades trans y mucho menos a las personas intersexuales, lo cual implica invisibilidad y, por tanto, la pérdida de derechos. Butler (2002: 162) señala que "el 'sexo' siempre se produce como una reiteración de normas hegemónicas". Dicho de otro modo, la categoría de sexo debe producir al mismo tiempo identidades, es decir, los sujetos deben asumir una identidad frente a esta norma social.

Aunado a lo anterior, la diversidad sexual no aparece como un tema a revisar en el programa de la asignatura. En ese sentido, se legitima la heterosexualidad en la enseñanza de la sexualidad y se invisibiliza la diversidad sexual. El hecho de que la diversidad sexual no se aborde de manera legítima en el programa de estudios es consecuencia del enfoque reproductivo de la sexualidad; es decir, mirar a los cuerpos y a las personas de acuerdo con su genitalidad. Es importante resaltar que, a pesar de los avances que se tienen en México en cuanto a derechos humanos de las poblaciones LGBTI, la educación en las escuelas normales no los contenga en su currículum ni en sus pedagogías. Estas carencias ocurren principalmente en la incongruencia que tienen los programas y planes con el contexto actual y con la importancia de una formación ciudadana de la sexualidad:

4 En la página de la Dirección General de Educación Superior para Profesionales de la Educación (DGESPE-SEP), aparece que este plan de estudios se derivó del Programa para la Transformación y el Fortalecimiento Académicos de las Escuelas Normales, en los compromisos expresados en el Plan de Desarrollo Educativo 1995-2000. Esto denota la desactualización que tiene el plan de estudios en todas sus especialidades. Para más información, sugiero revisar: http://www.dgespe.sep.gob.mx/planes/les 
¿Cómo veo los programas? ¡Pues mancos! Hay que ampliarlos, hay que actualizarlos. Por ejemplo, el curso de Desarrollo II. Crecimiento y Sexualidad, nadie les dice a mis alumnos cómo hablar con los adolescentes esto y cómo explicarles, por ejemplo, qué hacer con las sensaciones, con el dolor, con las dudas, eh, cuánto tiempo va a durar. ¿Cómo veo Desarrollo V? ¡Manco! El programa no aborda las situaciones de riesgo en cuanto a sexualidad. En cuanto a identidad, por ejemplo. ¿cómo la vive un adolescente en la formación de su identidad? (Mujer, docente, 44 años).

La docente entrevistada manifestó su preocupación por la manera en que se aborda la sexualidad en la formación de docentes. Recalcó que, aunque revisan una larga tira de materias sobre la adolescencia, es poca la información que tienen sobre cómo conocerse a sí mismos y de qué modos orientar a los adolescentes que tendrán como estudiantes.

De manera semejante, me parece importante señalar que en la asignatura "Atención educativa a adolescentes en situaciones de riesgo" (SEP, 2001b), la violencia hacia las orientaciones sexuales e identidades de género no hegemónicas no aparece como una situación de riesgo. De acuerdo con el programa de la materia, existe una necesidad de formar "educadores de adolescentes" basándose en la observación y en el análisis de la vida escolar. También se enuncia que dicha materia tiene como finalidad que los futuros profesores tengan apertura y comprensión respecto de la diversidad que existe entre sus estudiantes. No obstante, las situaciones de riesgo en las que hace hincapié el programa son "delincuencia, adicciones y homicidio", sin mencionar sexismo, discriminación por orientación sexual o identidad de género.

Teniendo en cuenta que la formación en sexualidad que recibe el estudiantado tiene carencias en contenidos curriculares, es pertinente recalcar la necesidad de actualizar los programas de estudio. La desinformación sobre estos temas medulares provoca ignorancia y la reproducción de la heteronormatividad, lo cual afecta a todos y todas sin importar identidades de género y orientaciones sexuales:

No saben ni qué hacer con su sexualidad. Hay "autohomofobia". ${ }^{5}$ Hay desconocimiento, producto de esta sociedad tapada de heterosexista, o que les explican los cambios que van a tener, pero no les dicen más. Es muy común entre mis alumnos que se preguntan y se resuelven entre ellos. Cualquier tema de sexualidad, ya sea de reproducción humana, de anticonceptivos, de orientaciones, de expresiones (Mujer, docente, 44 años).

Considerando el sentir de la docente que imparte la asignatura sobre sexualidad, es preciso generar cambios en el enfoque del programa para que en los programas de las asignaturas rela-

5 También se le llama homofobia interiorizada: "miedo, prejuicio, rechazo y desprecio irracional que algunas personas homosexuales sienten hacia sí mismas y hacia otros gays y lesbianas" (Gómez, 2009: 43). En este tenor, la homofobia interiorizada es producto de la heteronormatividad en la vida de las personas LGBT. En el siguiente capítulo describiré cómo un estudiante homosexual puede mostrar actitudes transfóbicas puesto que acepta ser homosexual, pero estigmatiza a las personas que no cumplen con los estereotipos de género.

Diálo Pos 
cionadas se aborden temas como ciudadanizar el derecho a la diferencia o, dicho de otro modo, el derecho a la diversidad. La sexualidad está presente en cada momento de la cultura escolar, el hecho de no abordarla o aprender sobre esta implica invisibilizarla. Es permitir la preservación de un modelo que limita el ejercicio, la manifestación y el disfrute del placer en la sexualidad.

\title{
La heteronormatividad en la escuela: Ia diversidad sexual como otredad sexual
}

¿Por qué la diversidad sexual es vista como la "otredad de la heterosexualidad"? Para responder un poco a esta pregunta me apoyo en la postura de Núñez (2016: 39), pues sustenta que en el lenguaje cotidiano existen tres usos comunes en los que se utiliza el término diversidad sexual: el primero, como un eufemismo; el segundo como sombrilla; ${ }^{6}$ y el tercero como referencia "a la otredad de la trilogía de prestigio macho-masculino-heterosexual". Este uso del término diversidad sexual como otredad de la heterosexualidad se debe a este modelo hegemónico en el que desde la heterosexualidad se fijan las normas a seguir:

\begin{abstract}
El heterosexismo configura un sistema de identidad: "el heterosexual vs. los otros" (algo que ha atrapado el habla popular cuando se dice "es de los otros" para referirse precisamente a los homosexuales), que coloca en el plano simbólico la heterosexualidad como la identidad central, única, normal, natural, completa, absoluta del ser, al grado de que ni siquiera tienen que decir su nombre (¿cuántos varones o mujeres van por la vida diciendo "soy heterosexual"?). Al utilizar la expresión diversidad sexual para referirnos sólo a unos grupos particulares, los "no heterosexuales", estamos actualizando en un lenguaje eufemizado y sanizado las dicotomías adentro-fuera, centro-periferia, uno-otro, completo-carente, del heterosexismo (Núñez, 2016: 47).
\end{abstract}

Avanzando en este razonamiento sobre la centralidad de la heterosexualidad como norma, tomo también la definición de etnocentrismo que hace Todorov (1991: 21), especialmente cuando se refiere a que consiste en el "hecho de elevar, indebidamente, a la categoría de universales los valores de la sociedad a la que yo pertenezco". Acorde con lo anterior, al reflexionar sobre el etnocentrismo escolar y sexualidad, me refiero a la postura que toma el estudiantado, el personal docente y las autoridades educativas frente a las identidades de género y orientaciones sexuales no hegemónicas. Al ser miradas como la otredad de la heterosexualidad $-\mathrm{y}$ sin tomar en cuenta que esta forma parte de la diversidad sexual-, se reproduce y legitima la heteronormatividad en la cotidianeidad de la vida escolar.

6 En relación con el eufemismo, el autor refiere que el término diversidad sexual se utiliza como "forma decente" para referirse públicamente a individuos o grupos estigmatizados con palabras consideradas vulgares" (Núñez, 2016: 39). Al mismo tiempo, señala que diversidad sexual se utiliza como término sombrilla "para una diversidad de identidades sociales, históricas y políticas, portadoras de sus propias limitaciones y posibilidades libertadoras, no completamente exploradas en sí mismas" (Núñez, 2016: 44). 
Retomando la idea de Núñez sobre los tres usos comunes del término diversidad sexual, yo agrego un cuarto: el término también se emplea para referirse únicamente a la homosexualidad masculina, dejando de lado la homosexualidad femenina (mujeres lesbianas), la bisexualidad, la transgeneridad, la transexualidad y la intersexualidad. Mi planteamiento es con base en la referencia que tomaron mis informantes en el momento en que yo les hacía preguntas con respecto a la diversidad sexual. El referente para ellos era binario: homosexualidad-heterosexualidad.

Durante una entrevista con un profesor de la Normal, me llevé varias sorpresas al escuchar su postura frente a la sexualidad, en general, y a la homosexualidad en particular. Esto tiene que ver con lo que socialmente se construye como normal y patológico. De entrada mostró rechazo para hablar sobre el tema, fue muy intransigente pues ni siquiera se sentó durante la entrevista: "Formalmente, aquí si no trata eso, no trata en la escuela, no trata casos, que la sexualidad que tenga que discutirse. Sobre todo, en la Normal no se discute eso, se acepta inmediatamente" (Hombre, docente, 65 años).

Enseguida discutió sobre el enfoque de mi investigación, y llegó el punto en el que se refirió a la homosexualidad como una anormalidad:

Entrevistador: Personas normales, cual... ¿quiénes son las personas normales?

I: Usted tendría que definirlas, igual como yo defino también mis esquemas.

E: Es que primero dice homosexuales, platique con homosexuales y después con personas normales.

I: Que no sean homosexuales. Usted tiene que decir sí y no, es una combinación binaria, sí y no. ¿Quién

es y por qué tiene tendencias? Y si es completamente respetable. No estar juzgando. Eso digo yo, mis respetos. Yo lo manejaría así, no puedo manejarlo de otra forma porque sería falsear mi investigación. Si yo lo hiciera tendría que ser así (Hombre, docente, 65 años).

De acuerdo con las palabras del profesor, se refirió a la homosexualidad como a una anormalidad y, para que yo diera validez científica a la investigación, argumentó que debía comparar a mis informantes homosexuales con heterosexuales, a quienes el informante considera "personas normales". Más adelante mencionó que si un estudiante es homosexual debe remitirse con un médico para que sea tratado:

I: Yo en lo particular lo abordo de la forma acostumbrada como son los otros, eh, de forma discreta, de forma social, y si pide orientación el alumno se le remite con un especialista, sobre todo el doctor.

E: ¿Por qué el doctor? ${ }^{7}$

I: Con el doctor, ¿quién es la persona más cercana a él que puede preguntar? Ya debe el chico preguntar a los doctores o a los especialistas. Yo supongo, porque no es mi caso (Hombre, docente, 65 años).

7 Aunque él usó el término "doctor", se sabe que en México así se les llama a los médicos. Además de que no se refería a una persona con estudios de doctorado sino específicamente a los profesionales de la medicina. 
Persiste la idea de que la homosexualidad es una enfermedad, algo que se puede curar, pero que al mismo tiempo se debe prevenir:"de hecho, como la homosexualidad existe hay que tomarla en cuenta y hay que estudiarla, pero no hay que propagarla". Incluso menciona que su abordaje es "de forma discreta", o sea, debe permanecer en lo privado.

Algo semejante ocurrió con otros dos informantes que hablaron sobre la diversidad sexual - centrándose en la homosexualidad masculina - como otredad de la heterosexualidad. En el primer caso, la informante trató de mostrarse incluyente; sin embargo, su discurso reveló etnocentrismo: "Si alguien tiene una preferencia sexual diferente y le decimos que eso está mal, eso es malo, o debes de ocultarlo, no debes de demostrarlo. Entonces nosotros estamos dando un autoconcepto negativo de un tipo de preferencia que tiene" (Mujer, docente, 40 años).

En el segundo caso, el profesor expresó que "ni ellos se meten con los de preferencia sexual diferente, ni los de preferencia sexual diferente se meten con ellos". Cuando habló de "ellos" se refería a sus estudiantes heterosexuales. Hay que recalcar aquí que los informantes usan la palabra diferente cuando se refieren a un estudiante con orientación sexual no hegemónica. En ese sentido, la heterosexualidad continúa siendo el centro, lo que no tiene problema pues no necesita ser aceptada, mientras que lo diferente 8 se ve como algo tolerado. Aunque la tolerancia no incluye aceptación, pues lo diferente, como dice Nieto (2013: 59), "emerge de un proceso social que dicta normas y emite leyes. Aquellos que violan el dictado de las normas son los desviados, en tanto que la violación de las leyes es el resultado de la acción de los delincuentes". Señalo entonces, que esta construcción normalizada permite mirar a los "diferentes" como seres que merecer ser soportados, ${ }^{9}$ esto significa una acción en la que se permite que el otro sea diferente, pero no es aceptado:

Toleran un poco más, ¿no?, pero en el closet donde también viven. Pero pues no lo manifiesto públicamente porque sé que hoy, mediáticamente he aprendido que no debo hacerlo, pero no porque esté convencido de ello. Entonces si lo comentamos en lo cortito, pues si me puede ser: ¡pinche maricón! ¡pinche lesbiana! ¡Y pinches todos los que no sean como yo! Pero en foros ya más formales, definitivamente, a lo mejor el discurso sería "sí, la tolerancia, el respeto, hacia los demás". Pero es puro lodo, es hueco todo eso. No es cierto (Hombre, docente, 65 años).

Con lo anterior quiero subrayar que las instituciones legitiman ciertas formas para entender y construir al otro con base en las ideologías propias. Por esto, la heteronormatividad es instituida en la escuela a través de diferentes dispositivos de poder que tienen que ver con el género, la sexualidad y el cuerpo. Esta mirada etnocentrista sobre la sexualidad categoriza,

8 "Para los normales, lo diferente altera su tranquilidad" (Piña, 2011: 15).

9 La tolerancia es una relación de poder en la que quien tolera está perdonando la vida del otro (Skliar, 2011). 
estigmatiza y violenta al otro, de acuerdo con las normas morales y sociales sobre cómo deben ser, sentirse y asumirse.

\section{La plumofobia en la formación docente: maestros no femeninos, maestras no masculinas}

La formación de docentes se encuentra llena de expectativas con base en lineamientos pedagógicos: a) habilidades intelectuales específicas; b) dominio de los propósitos y los contenidos de la educación secundaria; c) competencias didácticas; $d$ ) identidad profesional y ética; y e) capacidad de percepción y respuesta a las condiciones sociales del entorno de la escuela (SEP, 1999). No obstante, dentro del currículo oculto ${ }^{10}$ existen también lineamientos que idealizan el papel del docente a través de normas sociales, las cuales preservan la cultura heteronormativa. Una de estas normas está íntimamente establecida sobre los roles de género y del cuerpo pues, de acuerdo con Bourdieu (2000: 22), "el mundo social construye el cuerpo como realidad sexuada y como depositario de principios de visión y de división sexuantes".

Sirva este planteamiento para pensar acerca del papel de la Escuela Normal como una institución heteronormativa que cumple con el "buen encauzamiento" y con la normalización de los sujetos y de sus cuerpos. Por esto, quienes forman a las y los futuros docentes, son asimismo vigilados: "este sistema hace 'resistir' al conjunto, y lo atraviesa íntegramente por efectos de poder que se apoyan unos de otros: vigilantes perpetuamente vigilados" (Foucault, 2009: 207).

Una de las prácticas comunes de la heteronormatividad es la plumofobia, la cual se define como "un tipo específico de homofobia que permite a las personas homosexuales tener relaciones con personas de su mismo sexo, pero no realizar roles que no se corresponden con su género" (Pichardo, 2009: 24). Dicho de otro modo, a través de la plumofobia se prohíbe la manifestación de expresiones corporales femeninas en hombres y de expresiones masculinas en mujeres, pues se cree que esto rompe con los estereotipos de género.

Los anteriores conceptos se ejemplificarán de manera etnográfica dado que en el trabajo de campo encontré una constante preocupación del profesorado con respecto a la imagen con la que deben cumplir los y las docentes de acuerdo con su género. Entrevisté a una profesora que imparte las asignaturas sobre sexualidad y adolescentes en situaciones de riesgo. Me parecía muy interesante escuchar qué pensaba dada su experticia en el tema.

Para empezar, mencionó que ella es una persona que está a favor del respeto a las personas con "preferencia sexual diferente"; sin embargo, para ella es trascendental que el estudiantado se adapte a las normas sociales:

10 De acuerdo con Sacristán (1987: 33) se entiende que el currículum oculto"es un conjunto de actividades y contenidos de enseñanza-aprendizaje no intencionadamente planeados o abiertamente reconocidos, que socializan a los individuos en la aceptación básica de las estructuras sociopolíticas y culturales dominantes, así como en la internalización selectiva de sus significados, normas y valores". 
Si se les van metiendo un poquito en habilidades sociales, como es que en ocasiones tenemos que respetar las normas sociales. Porque a mí me parece que, en ocasiones, los que se manejan, así como si fueran "locas", por decirlo así de alguna forma muy expresiva, "iAy!" [Imita], así que muy expresivos, tú les tienes que guiar en ese proceso de decir: está bien que tú tengas una preferencia diferente, pero debemos tener como cierto tipo de formas de convivencia común y de respeto hacia todos" (Mujer, docente, 40 años).

Este planteamiento conduce a la idea de que si un estudiante hombre -independientemente de que sea homosexual o no- debe ser masculino, por tanto, si se muestra con pluma, es decir, afeminado, está incumpliendo con las normas sociales, entre las que se encuentra el respeto a los demás. Pero ¿por qué está siendo irrespetuoso al tener pluma? Es entonces cuando se piensa en la plumofobia, dado que se tolera medianamente que alguien sea diferente, pero que no exprese su diferencia porque es molesta. De hecho, la profesora imitó un grito para dejar claro que eso es inadecuado para un profesor. Estos discursos se basan en el androcentrismo ${ }^{11}$ dado que la preocupación del personal docente es mayor porque los estudiantes varones sean normados, dejando de lado a las estudiantes lesbianas que se expresan de manera masculina (desde la construcción social del género).

En ese orden de ideas, si un estudiante es afeminado debe entender que si no es aceptado por sus pares es consecuencia de su comportamiento y está obligado a cambiarlo. De no ser así, él mismo es culpable de que se le discrimine:

Entrevistador: Eso de las normas sociales o de las manifestaciones que usted dice de las personas con preferencias diferentes, ¿se refiere a esas manifestaciones que tienen dentro de la escuela o en general? Informante: ¡Dentro de la escuela! Por ejemplo, cuando hacen expresiones así muy notorias y tú ves que empiezan como a afectar de cierta forma ¿si?, o a molestar a los otros, es cuando tú les guías para que modifiquen esas actitudes y sean más aceptados [...] Los maestros tenemos que enseñar habilidades sociales para que lo puedan, puedan ellos ser aceptados de forma adecuada (Mujer, docente, 40 años).

Prosiguiendo con este análisis, otro profesor mencionó que conocía a un "alumno travesti" en otra institución de educación superior y que tenía el interés de visitarlo en la Escuela Normal, pero el profesor se negó a recibirlo porque estaba incumpliendo con las reglas de su institución de trabajo: "O te me vistes bien porque si no puede ocurrir un problema, que se pueden burlar de ti, que te van a faltar al respeto" (Hombre homosexual, docente, 57 años). Algo que me quedó claro es que el "alumno travesti" que el profesor tenía en otra escuela no era una persona

11 De acuerdo con Núñez (2016: 36), el androcentrismo "es la ideología y práctica que naturaliza y establece socialmente el predominio de los hombres y lo masculino sobre las mujeres y lo femenino". 
que se asumiera como hombre, sino que era una mujer trans, pero el profesor desconocía el término y por eso le llamó en masculino. Incluso, quiso corregir el uso del término transexual por travesti.

Creo que, de alguna forma, la vestimenta, la apariencia de la persona tiene que ir pues adecuada a su persona, ¿no? Háblese de hombre, háblese de mujer. Creo que, en ese sentido, es un poco complicado por todo, insisto, los tabúes, por todo lo que puede haber, aquí hay alumnos que son homosexuales y que vienen pues con vestimentas de mujer, o sea, son como que tratan de llegar a ser transexuales, digo travestis. No me atrevo porque nada más lo veo de apariencia ¿no? [quiso corregir el uso de transexual por travesti]. Entonces creo que ahí sí debemos tener cuidado por lo que pueda ocurrir en la secundaria, en sus prácticas, en sus visitas, o sea, tenemos, o sea solamente tenemos que mantener esa imagen (Hombre homosexual, docente, 57 años).

Otra profesora, quien se muestra con una postura más abierta acerca de la diversidad sexual, plantea su preocupación sobre la exigencia que tiene la Escuela Normal respecto a las reglas sociales sobre la imagen del docente. Es decir, los docentes están obligados a hacer cumplir las normas, aunque discrepen de ellas:

Hostigamiento hacia los alumnos amanerados porque van a las prácticas y quieren que yo hable con ellos para obligarlos a que se comporten como varones. No sé en qué parámetro. Chicas, que, por favor, se vistan adecuadamente. ¿Qué es lo adecuado? O sea, ¡basta con el uniforme! (Mujer, docente, 40 años).

Por su parte, quien se encuentra a cargo del Departamento de Psicopedagogía expresó que conoció un estudiante al que tuvo que orientarlo para que cambiara su comportamiento de homosexual con pluma:

Era muy dedicado, sí era desastroso [se ríe]. De pronto era así como muy amanerado, muy expresivo, y eso de pronto no le caía muy bien a algunos maestros compañeros. ¡Sé mesurado! ¿no?, tranquilo, controla un poco más tu impulso. Situaciones esas ahí como que él tendría que ir manejando ya propiamente dentro de su formación (Mujer, docente y administrativa, 40 años).

Estas prácticas de vigilancia heteronormativa tienen un claro ejemplo de la visión patologizante sobre la homosexualidad, pues al recomendar que el estudiante controle sus impulsos se espera que normalice sus impulsos. Algo semejante ocurre desde la experiencia de un estudiante homosexual. A él le gusta llevar una variedad de bolsas a la Escuela Normal, lo cual representa un peligro para la imagen que debe aprender como futuro docente. Considerando

Diálo@os sobre Educación año 11 | número 21 | julio-diciembre 2020 | ISSN 2007-2171 
esto, me describió la manera en la que un profesor le llamó la atención para que dejara de hacerlo:

¿Por qué traes bolsas de mujer? Y le dije: no es bolsa de mujer. Y sí me dijo: es que, si vas para maestro, compórtate como tal, mas si tu preferencia sexual la quieres llevar, llévala muy afuera, pero aquí compórtate como tal. Y yo lo único que le dije: yo me comporto como lo que sea, porque el hecho de que yo voy para maestro, aquí no dejo de ser alumno, y en un salón de clases puedo ser diferente porque tengo la madurez suficiente de comportarme en cada rincón, en cada momento como yo quiero (Hombre homosexual, estudiante, 23 años).

Pareciera que la postura del estudiante es totalmente agenciada sobre la forma en la que gusta vestirse dentro de la Escuela Normal. A pesar de que muestra cierta resistencia frente a la normalización, él mismo mencionó que cuando se encuentre en un salón de clases como docente asumirá el modelo que le encauzaron. Aquí es interesante invitar, a modo de reflexión, al planteamiento de Rofes (2005: 144): “Parecería que el personal docente tiene que cumplir sólo con uno de los roles de género estipulados. Lo importante aquí es señalar que la resistencia frente a lo heteronormativo puede permitir transformaciones sobre el deber ser de los maestros".

Estos planteamientos me hacen compararlos con la postura de Foucault (2014) sobre las tres figuras que socialmente constituyen el ámbito de la anomalía; entre estos está el individuo a corregir - y aunque no representa tanta monstruosidad para el ser anormal en el siglo XIX-, debe someterse a técnicas de recuperación y corrección mediante la familia o la institución que esté a su cargo. Para estos casos, la escuela debe ejercer el poder y hacer cumplir la norma: "siempre está ligada a una técnica positiva de intervención y transformación, a una especie de proyecto normativo" (Canguilhem, 1972, citado por Foucault, 2014: 57).

\section{Homofobia, lesbofobia, bifobia y transfobia en la Normal: Consecuencias} de la normalización de la sexualidad

La normalización de la sexualidad en la formación docente —además de las prácticas sutiles de encauzamiento del cuerpo - también se legitima a través de otras prácticas en las que estudiantes gays, lesbianas, bisexuales y trans son violentados. En otras palabras, este enfoque hegemónico tiene como consecuencia que exista la homofobia, la lesbofobia, la bifobia y la transfobia $^{12}$ en las instituciones educativas.

Estas formas de violencia se ejercen tanto de estudiantes a estudiantes como de docentes a estudiantes, y viceversa. Aunque son los docentes quienes aprovechan su poder para demos-

12 Quizá parezca un juego de palabras esta lista de violencia hacia las personas LGBT, pero prefiero nombrar a todas y no solo quedarme en la homofobia. Eso demostraría una centralidad solo en la homosexualidad masculina. 
trar a los estudiantes que deben corregir sus formas de ser y estar en la escuela, a menos de que quieran ser discriminados. Por una parte, la jefa del Departamento de Investigación y Experimentación Educativa expresó que un profesor se opuso a asesorar el documento recepcional de un estudiante homosexual:

Porque el problema no es cosa solamente de sexualidad o de homosexualidad, que eso lo hay, ¿no? O sea, tuve algún alumno de séptimo semestre, como de los que tengo ahorita, homosexual. Y obviamente un maestro de Matemáticas, dijo: ese es puto y yo no lo quiero tener como asesorado. Obviamente, porque pues son hombres. ¿Cómo vas a tener asesorado a una cosa de estas? O sea, ¡no! Son hombres y entonces quién sabe quién te vaya a asesorar. Nada más por su condición. Entonces obviamente pues, Gabriel fue mi alumno, es un alumno brillante. Sin duda, fue bastante pues discriminado por maestros de Matemáticas, pero bueno, vas checando, vas sobrellevando, pero independientemente de eso, digamos que finalmente, anula parcialmente sus derechos como alumnos, de ser asesorados, de tener un asesor, en fin (Mujer, docente y administrativa, 60 años).

Aquí existe una clara conciencia por parte de la profesora de que la homosexualidad no es un problema, más bien el problema es la violencia que se ejerce sobre las personas que tienen esta orientación sexual. Casos así demuestran que ser homosexual en la Normal podría tener implicaciones fuertes, al grado de ser discriminado y no poder ser asesorado, solo por los principios morales de un docente, en lugar de que cumpla con sus obligaciones para las cuales se le paga.

Por otra parte, una profesora mencionó también que esto puede implicar casos de reprobación como una represalia: "Hay maestros compañeros que pues obviamente es un abuso de poder porque un alumno se siente espantado ante un maestro. $Y$ el que no se siente espantado y está envalentonado, también lo espantan. Mínimo lo reprueban" (Mujer, docente, 40 años).

Si los docentes ejercen su autoridad para sancionar a estudiantes por el hecho de no ser heterosexuales, entonces la homofobia puede ser una causa de la deserción escolar. Esta misma profesora describió el caso de una estudiante transgénero que desertó de la formación docente porque no le permitieron asistir a la Normal como una mujer: "Ya hubo un caso de un chico que sí se vestía como mujer, lo detuvieron, puso una manta y cerró la escuela, lo detuvieron. No se tituló." (Mujer, docente, 40 años).

Si bien la docente reconoce que se trataba de una persona trans, está omitiendo que se trata de una mujer pues no se asumía con el género que culturalmente se le impuso de acuerdo con su genitalidad: "aproximadamente entre quince y dieciséis años, el muchacho pues iba de mujer a la secundaria" (mujer, docente, 40 años). Este caso de transfobia ocurrió, de acuerdo con la profesora, hace más de diez años, tiempo en el que aún no existía ninguna ley que protegiera los derechos de esta población de la diversidad sexual. La profesora se mostró siempre como 
una persona que está a favor de los derechos humanos y de los derechos sexuales. Compartió que, como consecuencia de su apoyo hacia estudiantes gays y lesbianas, ha sido víctima de acoso por parte de sus colegas, pues piensan que su apoyo es debido a que ella es lesbiana:

Yo he recibido discriminación por parte de otros maestros y de parte de autoridades, señalamientos, hostigamiento porque dicen que yo los apoyo y que les permito hacer todo. Incluso me han acusado a mis alumnos, "Oye, fíjate que, a ver si hablas con tus alumnas", "oigan, ¿pues qué estaban haciendo?", "nada, nada más abrazadas como siempre", entre chicas gays. Me han cuestionado en exámenes profesionales de por qué yo permito que continúen los alumnos amanerados y por qué no los corro de la escuela, que qué vamos a hacer con ellos. De ese tamaño, hay mucha homofobia en la escuela. [...] Y me acosaron los maestros, hicieron indirectas diciendo "Ya déjalos, al fin que hay muchos amanerados en la Escuela, así como maestras lesbianas" (Mujer, docente, 40 años).

Lo interesante del hostigamiento que ha recibido la profesora es que, aunque ella no se identifica como lesbiana, los demás piensan que lo es, por el apoyo que ha dado a estudiantes en situaciones de homofobia. Esto indica que la discriminación por orientación sexual o identidad de género también la sufren las personas heterosexuales, ya sea por sus posturas políticas, acciones y/o apariencia.

De manera similar, una estudiante lesbiana expresó que ha estado en situaciones de señalamiento por parte de sus pares. Ella trae un corte de cabello que pone en riesgo su imagen como futura maestra, pues no está actuando de acuerdo con sus roles de género tradicionales:

Informante: No me gusta que me digan que soy niño. De hecho, porque luego me molestan. Por mi corte que traigo. De que me dicen "ah, pareces niño", porque no sé qué...

Entrevistador: ¿Y tú qué piensas cuando te dicen eso?

Informante: Pues sí, no les digo o contesto feo, pero les digo que no me gusta que me digan niño o que me digan que parezco niño. Pero me lo han dicho como mis compañeras, haciéndome como broma, ¿no?, ipero siento que lo dicen en serio!

La diferencia del hostigamiento que ha recibido ella y el que han vivido los estudiantes gays es porque existe mayor preocupación por la imagen del maestro, o sea, del docente varón. La vigilancia hacia las mujeres lesbianas es menor; inclusive, mencionó que no ha recibido alguna llamada de atención por parte de docentes, sino que han sido sus compañeras quienes le critican por la forma en que viste y porta su cabello. El lugar donde recibió condiciones para su ingreso fue en la secundaria en la que iba a realizar sus prácticas. De tal modo que se vio obligada a cambiar su apariencia para ser aceptada en la institución: 
En la secundaria me dijeron eso, que no se permitían esos cortes. Porque el corte que yo traía antes, lo traía como rapado. Entonces me dijeron que no podía ir así. Entonces lo que hice solo fue peinármelo bien para que no se me viera mi lado rapado (Mujer lesbiana, estudiante, 19 años, segundo semestre).

Considero ahora que la vigilancia heteronormativa está más inclinada hacia el docente varón. Esto se puede confirmar con el caso de un estudiante bisexual. Desde que llegué a realizar trabajo de campo en la Normal, lo ubiqué visualmente, pues siempre traía el cabello teñido de colores como azul, rosado o morado. Esto ocurrió durante sus primeros dos semestres de la licenciatura pues no realizaba largas jornadas de práctica u observación en las secundarias. Así que se le permitía asistir a la Normal con su cabello teñido. El personal docente no tardó tanto en darle recomendaciones para que cambiara su apariencia pues representaba una falta al modelo del docente que están formando.

A pesar de que el estudiante muestra cierta resistencia frente a las normas de la institución sobre su apariencia física, está consciente de que debe cumplir con ello y termina aceptando. Tiempo después, volví a la institución y me dijo que ya no se pintaría más el cabello. Decidió seguir la rectitud por encima de sus ideas de resistencia ante la heteronormatividad puesto que incumplir la norma implica recibir la sanción, por tanto, el estudiante decidió asumir su papel como un futuro docente varón.

Quisiera finalizar este apartado con una reflexión que hace Butler (2006: 40-41), en la que señala lo vulnerable que puede ser el cuerpo en el marco del espacio público:

El cuerpo implica mortalidad, vulnerabilidad, agencia: la piel y la carne nos exponen a la mirada de los otros, pero también al contacto y a la violencia. El cuerpo también puede ser la agencia y el instrumento de todo esto, o el lugar donde «el hacer» y «el ser hecho» se tornan equívocos. Aunque luchemos por los derechos sobre nuestros propios cuerpos, los mismos cuerpos por los que luchamos no son nunca del todo nuestros. El cuerpo tiene invariablemente una dimensión pública; constituido como fenómeno social en la esfera pública, mi cuerpo es y no es mío.

En este tenor, considero que los informantes, ya sean estudiantes o docentes, asumen que están en un espacio público y compartido. Por ello deciden cumplir con lo heteronormativo aunque no estén de acuerdo con ello. En el marco de la Escuela Normal, la mayoría de los informantes están asumiendo los roles de género para así permanecer y no ser más violentados.

Sería muy interesante saber qué pasa con los y las docentes que se encuentran frente a grupo, es decir, aquellas personas que egresaron de la Normal y que están en el ejercicio docente: ¿Cumplen también con las normas? ¿asumen su rol como modelo heteronormativo en la escuela? ¿se agencian de sus derechos y resisten mediante la palabra, la expresión y el cuerpo? ¿cuáles serán las diferencias y similitudes entre la vida escolar de docentes LGBT en contextos rurales y urbanos? 
La norma, como dice Canguilhem (1971), no implica una imposición, es decir, la norma se legitima hasta que existe lo normativo: "aquello que instituye normas". Esta postura tiene similitud con lo que Butler (2006: 69) señala sobre la norma: "parece ser indiferente a las acciones que rige, con lo cual solo quiero decir que la norma parece tener un estatus y un efecto que son independientes de las acciones gobernadas por la norma". En ese sentido, ¿qué pasaría en la Normal si la cultura escolar no estuviera apegada a la heteronormatividad? Es necesaria una reflexión sobre la performatividad del género pues implica reconocer que existen otras maneras de ser, pensarse y sentirse.

\section{Reflexiones finales}

Las aproximaciones que se lograron a partir de este estudio en una escuela formadora de futuros docentes de educación secundaria, permiten comprender las diferentes realidades que viven día con día quienes trasgreden las normas sociales que construyen al otro de acuerdo con su orientación sexual e identidad de género.

Sin duda, la escuela es un espacio de lucha y resistencia ante las opresiones que el sistema patriarcal y androcentrista produce de manera jerárquica, encauzante y normalizante. Por un lado, dichas resistencias dan pauta para que otras personas tomen esos ejemplos de vida y trasgredan la norma para ser, sentirse y asumirse como realmente son. Por otro lado, se perpetúa el silencio de las voces de personas que transitan por estos espacios y que, por el contexto en el que se encuentran, no es posible que sean visualizados y nombrados.

La escuela Normal continúa siendo una institución que reproduce los estereotipos de género y vigila cada una de las expresiones que van más allá de lo socialmente establecido como masculino o femenino. De tal manera, resulta indispensable trasformar esos pensamientos para generar espacios de diálogo y de análisis que permitan el reconocimiento de la diversidad sexual en la escuela.

Es necesario dar visibilidad a cada una de las sexualidades que se manifiestan en las instituciones educativas, por tanto, quienes se desempeñarán como docentes están obligados éticamente a coadyuvar en la prevención y eliminación de la violencia hacia quienes incumplen con la heteronormatividad. En consecuencia, la formación inicial sobre sexualidad no debe quedarse exclusivamente en los aspectos biológicos, sino que es pertinente su abordaje desde las diferentes construcciones sociales e históricas, en lugar de continuar en la enseñanza normalizada de la sexualidad.

Definitivamente, es preciso enunciar que este sistema hegemónico no solo es producido por heterosexuales, sino que también personas que se asumen como lesbianas, gays, bisexuales o trans pueden reproducir los roles heteronormativos puesto que los internalizan a lo largo de su vida. En este tenor, es indispensable deconstruir el ideal del docente como un modelo heteronormativo. 
La construcción social de lo normal y lo patológico continúa siendo parte de la vida cotidiana en la institución, pues reproduce los patrones que marcan cómo debe ser y expresarse el personal docente acorde con su género. En la investigación educativa, denunciar la homofobia, la bifobia, la lesbofobia y la transfobia amerita repensar los ideales de la escuela —en todos los niveles educativos-, las posibles funciones de los actores que en esta se desenvuelven y los objetivos de la educación en general.

Es menester que se generen investigaciones enfocadas a visualizar la discriminación por orientación sexual e identidades de género no hegemónicas en las instituciones educativas de todos los niveles. Del mismo modo, es necesario analizar este problema no solo en contextos urbanos sino, también, en contextos rurales donde tanto estudiantes como docentes se enfrentan a situaciones distintas. Además, habría que abordar cómo se relaciona el tema de la LGBTfobia escolar con otras categorías referentes a lo étnico, el género, la migración, etcétera.

\section{Referencias}

Berger, P. y T. Luckmann (2012). La construcción social de la realidad. Buenos Aires: Amorrortu. Bourdieu, P. (2000). La dominación masculina. Barcelona: Anagrama.

Butler, J. (2006). Deshacer el género. Barcelona: Paidós.

Butler, J. (2002). Cuerpos que importan: Sobre los límites materiales y discursivos del "sexo". Buenos Aires: Paidós.

Canguilhem, G. (1971). Lo normal y lo patológico. México: Siglo XXI.

Carrera, M. V.; M. Lameiras; Y. Rodríguez (2013). Heteronormatividad, cultura y educación. Un análisis a propósito de "XXY". InterseXiones, (4), 45-76.

Flores, J. (2010). "La homofobia y las bases biológicas de la diferenciación sexual”: En Muñoz, J. (coord.). Homofobia, el laberinto de la ignorancia. México: UNAM.

Foucault, M. (2009). Vigilar y castigar. Nacimiento de la prisión. México: Siglo XXI.

Foucault, M. (2014). Los anormales. Buenos Aires: Fondo de Cultura Económica.

Geertz, C. (2003). La interpretación de las culturas. Barcelona: Gedisa.

Giddens, A. (2003). La constitución de la sociedad. Buenos Aires: Amorrortu.

Gómez, A. B. (2009). "Adolescentes lesbianas y gays frente a la homofobia". En Moreno, O.; L. Puche (eds.). Transexualidad, adolescentes y educación: miradas multidisciplinares. Madrid: Egales.

Hernández-Rosete, D.; J. Flores; L. Echavarría (2011). Sin pecado concebido. Sida y embarazo en el libro de sexo de ciencias naturales. Revista Mexicana de Investigación Educativa, 16(49), 471-488. http://www.scielo.org.mx/pdf/rmie/v16n49/v16n49a7.pdf 
Hernandez-Rosete, D.; N. Miscow (2015). Ser "emo" y estudiar en la Ciudad de México. Entre la violencia de estado y el miedo social a la otredad. En Gómez, N.A.; M. E. Pedraza (coords.). Género. Relaciones de pareja. Violencia en contextos universitarios. México: Universidad Autónoma de la Ciudad de México - ITACA.

Lizárraga, X. (2012). Semánticas homosexuales. Reflexiones desde la antropología del comportamiento. México: Instituto Nacional de Antropología e Historia.

Morgade, G.; G. Alonso (2008). Cuerpos y sexualidades en la escuela. De la "normalidad" a la disidencia. Buenos Aires: Paidós.

Muñoz, J. (2010). La ciencia hegemónica contemporánea y la homofobia. En Muñoz, J. (coord.). Homofobia, laberinto de la ignorancia. México: UNAM.

Nieto, J. A. (2013). Despsiquiatrizar el transgénero. En Moreno, O.; L. Puche (eds.). Transexualidad, adolescentes y educación: miradas multidisciplinares. Madrid: Egales.

Núñez, G. (2016). ¿Qué es la diversidad sexual? México: Paidós.

Pichardo, J. I. (ed.) (2009). Adolescentes ante la diversidad sexual. Homofobia en los centros educativos. Madrid: Los libros de la Catarata.

Piña, J. M. (2011). Aceptación, estigma y discriminación. Estudiantes normalistas ante sectores vulnerables. México: Díaz de Santos.

Rockwell, E. (2009). La experiencia etnográfica. Historia y cultura en los procesos educativos. Buenos Aires: Paidós.

Rofes, E. (2005). La transgresión y el cuerpo ubicado: El sexo, el género y los profesores varones gays. En Talburt, S.; S. R. Steinberg (eds.). Pensando queer. Sexualidad, cultura y educación. Barcelona: Graó.

Sacristrán, A. (1987). En torno al currículum oculto. Madrid: Morata.

Sánchez, M. (2009). Cómo educar en la diversidad afectivo-sexual en los centros escolares. Orientaciones prácticas para la ESO. Madrid: Los Libros de la Catarata.

Secretaría de Educación Pública (1999). Licenciatura en Educación Secundaria. Plan de estudios 1999. Documentos básicos. México: SEP.

Secretaría de Educación Pública (2001a). Desarrollo de los Adolescentes I. Aspectos Generales - Desarrollo de los Adolescentes II. Crecimiento y Sexualidad. Programas y materiales de apoyo para el estudio. Licenciatura en Educación Secundaria. $1^{\circ}$ y $2^{\circ}$ semestres. México: SEP.

Secretaría de Educación Pública (2001b). Atención Educativa a los Adolescentes en Situaciones de Riesgo. Programa y materiales de apoyo para el estudio. Licenciatura en Educación Secundaria. $5^{\circ}$ semestre. México: SEP.

Skliar, C. (2011). ¿Y si el otro no estuviera ahí? Notas para una pedagogía (improbable) de la diferencia. Buenos Aires: Miña y Dávila Editores.

Taylor, S. J.; R. Bogdan (1994). Introducción a los métodos cualitativos de investigación. Barcelona: Paidós. 
Todorov, T. (1991). Nosotros y los otros. México: Siglo XXI.

Vigarello, G. (2005). Corregir el cuerpo. Historia de un poder pedagógico. Buenos Aires: Nueva Visión.

Werner, E. (2008). Homofobia y convivencia en la escuela. Bogotá: Universidad Pedagógica Nacional. Wittig, M. (2006). El pensamiento heterosexual y otros ensayos. Barcelona: Egales. 